\title{
An Update on Oxidative Damage to Spermatozoa and Oocytes
}

\author{
Chinyerum S. Opuwari and Ralf R. Henkel \\ Department of Medical Biosciences, University of the Western Cape, Robert Sobukwe Road, Bellville 7530, South Africa \\ Correspondence should be addressed to Ralf R. Henkel; rhenkel@uwc.ac.za
}

Received 4 November 2015; Revised 28 December 2015; Accepted 11 January 2016

Academic Editor: Monica Muratori

Copyright (C) 2016 C. S. Opuwari and R. R. Henkel. This is an open access article distributed under the Creative Commons Attribution License, which permits unrestricted use, distribution, and reproduction in any medium, provided the original work is properly cited.

\begin{abstract}
On the one hand, reactive oxygen species (ROS) are mandatory mediators for essential cellular functions including the function of germ cells (oocytes and spermatozoa) and thereby the fertilization process. However, the exposure of these cells to excessive levels of oxidative stress by too high levels of ROS or too low levels of antioxidative protection will render these cells dysfunctional thereby failing the fertilization process and causing couples to be infertile. Numerous causes are responsible for the delicate bodily redox system being out of balance and causing disease and infertility. Many of these causes are modifiable such as lifestyle factors like obesity, poor nutrition, heat stress, smoking, or alcohol abuse. Possible correctable measures include foremost lifestyle changes, but also supplementation with antioxidants to scavenge excessive ROS. However, this should only be done after careful examination of the patient and establishment of the individual bodily antioxidant needs. In addition, other corrective measures include sperm separation for assisted reproductive techniques. However, these techniques have to be carried out very carefully as they, if applied wrongly, bear risks of generating ROS damaging the germ cells and preventing fertilization.
\end{abstract}

\section{Introduction}

One of the downfalls of all assisted reproduction techniques (ARTs), particularly intracytoplasmic sperm injection (ICSI), is thought to be the fact that genetically and/or chromosomally damaged spermatozoa may fertilize an oocyte by bypassing all the physiological selection barriers in place in the female organism to prevent such event (for review see [1]). The likelihood of using DNA-damaged spermatozoa in ICSI is much higher since the DNA fragmentation rate is significantly higher in patients with poor semen quality $[2,3]$ and the DNA damage cannot be recognized while selecting spermatozoa for this process [4] and since there is no practical, nonconsumptive test available that can successfully exclude DNA-damaged spermatozoa from being selected by the embryologist for the injection procedure $[5,6]$. Besides affecting fertilization and the outcome of pregnancy, sperm DNA damage has a negative impact on the health of the offspring as uncorrected sperm DNA damage following zygote formation has the potential to create mutations/epimutations in the offspring [7]. This has been shown for intrauterine insemination (IUI), in vitro fertilization (IVF), and ICSI, and increased incidences of chromosomal abnormalities, minor and major birth defects, or early childhood cancers, particularly in the male offspring, have been linked to these procedures [8-16]. The level of sperm DNA fragmentation may give a sense of guidance as to the appropriate method of ARTs to employ especially between IVF and ICSI $[17,18]$. As a result, numerous authors have suggested an introduction of sperm DNA damage testing into the andrological laboratory workup as an independent tool as DNA fragmentation apart from normal sperm morphology appears to be a reliable and more robust parameter than conventional semen analysis due to its low biological variability and thus is a useful biomarker that should be implemented in any andrological diagnostic workup [1921]. Furthermore, sperm DNA damage appears to be linked to the most important checkpoints of fertility such as reduced fertilization rates, lower embryo quality and pregnancy rates, higher miscarriage rates, malformations, and childhood diseases [22].

Evidence continues to suggest that ART does increase risk of higher order pregnancy (with its inherent pre- and perinatal risks), prematurity and low birth weight, congenital malformations, in particular of the male urogenital system, and 
imprinting disorders [23-26]. Paternal sperm DNA damage has negative effects on the integrity of early embryonic development as the percentage of good quality embryos as well as implantation rates was significantly reduced in patients exhibiting high DNA damage [27] and it appears that the second and third mitoses are the sensitive periods [28]. Ghaleno et al. (2014) showed that the intracellular levels of hydrogen peroxide $\left(\mathrm{H}_{2} \mathrm{O}_{2}\right)$ and superoxide $\left(\mathrm{O}_{2}{ }^{-\bullet}\right)$ correlate negatively with impaired sperm mitochondrial membrane potential leading to poor-quality pronuclear embryos [29]. However, only $\mathrm{H}_{2} \mathrm{O}_{2}$ interfered with pronuclear formation. Reassuringly, evidence points away from an increased overall cancer risk or differences in neurodevelopmental outcomes. However, many unknowns remain, including future fertility and cardiovascular risks and risk of cerebral palsy [30].

On the other hand, very recent data suggest that the observed increased frequency of birth defects, congenital malformations, and chromosomal abnormalities after assisted reproduction might be due to confounders [31,32]. It appears that the increase in birth defects because of increased sex chromosome abnormalities is due to the assisted reproduction protocol per se rather than to the biological perturbations [33]. Yet in the absence of indubitable evidence of no increased risks it is mandatory to investigate the possible influence of the male genome on the health of the offspring with a suitable test.

Considering the inconsistent data situation, the existence of a variety of different assays that test for different aspects of sperm DNA fragmentation [34], and a lack of standardization and clinical evaluation, which makes it difficult for clinicians and scientists to decide which assay would be the best for clinical implementation [21], it is mandatory in the best interest of both prospective parents and the future offspring to implement a test to evaluate the extent of sperm DNA damage. Furthermore, there is still an urgent need for scientists to understand the principle on which the respective assays are based and which aspects of DNA damage these tests measure [4]. The various tests employed for DNA damage, the level at which sperm DNA damage may occur, assay principles, and the advantages and disadvantages thereof have been reviewed [4].

In this context, numerous reports have been published on the impact of oxidative stress on spermatozoa (for review see [35-38]) with its beneficial and detrimental effects of reactive oxygen species (ROS) like $\mathrm{H}_{2} \mathrm{O}_{2}, \mathrm{O}_{2}{ }^{-}$, and/or the hydroxyl radical $\left({ }^{\circ} \mathrm{OH}\right)$ [39-41]. Yet most literature on oxidative damage to human gametes is focussing on sperm and less on the oocytes or the oocyte-cumulus complex. Nevertheless, it can be assumed that this point is not less important for the fertilization process, the onset of pregnancy, and the birth of healthy offspring.

\section{Oxidative Stress and Oocytes/Granulosa Cells}

It is well-known that ROS have both beneficial and detrimental effects in terms of important regulatory functions and playing a role in the origin and progression of diseases such as cancer, neurodegenerative diseases or deleterious effects in embryo development, respectively, not only on spermatozoa [42-46], but also on all other cells in the body including cells of the female reproductive tract such as granulosa cells or oocytes [47-49].

In this context, not only are ROS levels in the follicular fluid significantly highly elevated in follicles from which poor-quality embryos derived and can therefore be regarded as a marker to determine ovarian and follicular metabolic age [50], but also the antioxidant capacity correlates positively with pregnancy after intracytoplasmic sperm injection in healthy women with endometriosis $[51,52]$. Similar relationships were found in women with polycystic ovaries after IVF and ICSI $[48,53]$. Even the serum and follicular fluid content of vitamins $\mathrm{C}$ and $\mathrm{E}$ may be related to the success in assisted reproduction [53].

On the other hand, in light of a proper redox balance both ROS and antioxidants transduce signals and trigger physiological events. It could be shown that ROS produced by leukocytes in the follicle at ovulation induce oocyte maturation, whereas antioxidants inhibit resumption of meiosis [54], thus suggesting a close relationship in the ovary. Thus, for healthy oocyte development a proper interplay of ROS with relevant enzymatic antioxidants such as superoxide dismutase, catalase, glutathione peroxidase, or glutathione reductase maintains the levels of reduced glutathione (GSH) and thus inhibits atresia of antral follicles and granulosa cell apoptosis [55]. After the LH surge triggering ovulation, oocyte GSH concentration increases rapidly as GSH is essential for fertilization events and early embryo development as GSH depletion prevents sperm chromatin decondensation and formation of the male pronucleus [56-58] where GSH is important for the reduction of the disulphide bridges of the protamines in the sperm nucleus $[57,59]$.

Apart from the direct influence in the fertilization and oocyte maturation process and embryo development outlined above, oxidative stress has been implicated in ovarian steroidogenesis and luteolysis and therefore indirectly affects female fertility $[47,60,61]$.

\section{Factors Causing Sperm DNA Damage}

Factors that can cause DNA damage include apoptosis, improper DNA packaging and ligation during spermatogenesis and sperm maturation, and oxidative stress [62-66]. Reactive oxygen species (ROS) can be produced in an ejaculate by the spermatozoa via the normal leakage of electrons from the mitochondrial electron transfer chain from Complex I or III [67] or leukocytes [20, 68,69]. Eventually, overavailability of these oxidants caused by either an overproduction of ROS or underavailability of antioxidative protection by various scavengers leads to an imbalance of the extremely sensitive redox equilibrium and thus oxidative stress [35]. The overavailability of ROS and the underavailability of antioxidants, respectively, can be caused by diseases such as genital tract infections, by unhealthy lifestyle, or by the laboratory handling of the gametes in course of an assisted reproduction treatment.

Most of the focus in the literature is on the detrimental effects of ROS on spermatozoa. A target of direct ROS action is the polyunsaturated fatty acids in the plasma membrane 
$[70,71]$ leading to lipid peroxidation and direct loss of motility. In addition, ROS can also directly damage the gametes' DNA. On the other hand, indirect action via end products of lipid peroxidation leads to the formation of carbonylcontaining compounds such as malondialdehyde, various 4hydroxy-2-alkenals such as 4-hydroxynonenal and 2-alkenals [72] which are genotoxic and cancerogenic [73, 74], thus affecting male fertility and thereby possibly contributing to higher rates of malformations. Alternatively, ROS have the ability not only to decrease the activity of antioxidative enzymes [75], but also to damage mitochondrial DNA (mtDNA), which encodes 13 polypeptides essential for the electron transfer chain on the inner mitochondrial membrane and is, therefore, intimately involved in oxidative phosphorylation and ATP production in the mitochondria. Hence, mtDNA defects will inevitably result in a decreased mitochondrial membrane potential $(\Delta \Psi m)$ thereby throwing the redox balance into the direction of oxidative stress. Defective mitochondrial function is essential for sperm motility [76] and has been suggested as a sensitive sperm parameter [77].

An association between male subfertility and infertility with the presence of genital tract infection and an increased number of leukocytes exists even though other scholars have on the contrary shown that seminal plasma leukocytes have no impact on the sperm fertilizing capacity [78]. The seminal plasma contains natural antioxidant such as vitamins $\mathrm{C}$ and $\mathrm{E}$, superoxide dismutase, glutathione, uric acid, and polyamine spermine which act as a free radical scavenger. Spermatozoa depend on this scavenging system provided by the seminal plasma after normal ejaculation in vivo [20, 68, 69, 79-81]. Besides fertility, leukocytes negatively correlate with semen quality, PMN elastase, and ROS by secreting cytokine. Leukocytes produce 1,000 times more ROS than spermatozoa [82, 83], yet there is a stronger correlation between the percentage of ROS producing spermatozoa and sperm DNA damage than those from leukocyte derived ROS production [84]. In terms of the percentages of DNA damage, it was recommended that testicular sperm rather than ejaculated spermatozoa be used for ICSI [85].

Other factors that contribute to DNA damage are sperm storage and sperm separation techniques. Fresh semen samples were shown to have reduced levels of DNA fragmentation while the levels of DNA fragmentation increased after storage such that wet-ice freezing and snap-freezing had similar effect of the damage in comparison to cryopreservation by TESTyolk buffer with glycerol (TYBG) [85]. From a separation technique point of view, density-gradient centrifugation, swim-up, and density-gradient centrifugation followed by a swim-up reduced the rate of DNA fragmentation compared to the increasing effect in fresh and washed semen samples, with density-gradient centrifugation step followed by a swimup having the most significant effect [85].

\section{Sperm Separation Techniques}

Sperm separation from seminal plasma is an essential step for any assisted reproduction technique. Even in vivo, sperm are separated from the protective seminal fluid as the male germ cells move out of this milieu and thereby gaining fertilizing ability and the inhibiting decapacitation factors such as spermine or glycodelins, which are abundant in seminal fluid, are removed from the sperm plasma membrane [86-88].

Historically, the first sperm separation technique included up to two washing procedures in order to remove seminal plasma with subsequent resuspension of male germ cells [8688]. This was followed by the employment of more sophisticated methods using a swim-up procedure from the washed cell pellet in order to obtain sufficient amount of motile, functionally competent spermatozoa for IVF [89]. Following these first reports on human sperm separation, more sophisticated methods were developed to obtain sufficient amounts of motile, functionally competent spermatozoa for IVF.

Sperm selection for assisted reproduction should aim to minimize the risk of abnormal sperm participating in the process of fertilization with the ideal technique being able to eliminate nonviable spermatozoa, leukocytes, bacteria, and other sources of contamination [90]. According to Henkel [1] criteria for a "good" sperm selection include the following: elimination of seminal plasma, decapacitation factors and debris, ROS producing sperm, leukocytes, and bacteria, enrichment of functional sperm, cost-effectiveness, ease, and quickness to be performed, and allowance for larger volumes of ejaculates to be processed.

In each case, care must be taken when employing any of the different methods, also taking the specific situation of the individual patient into account. Currently, the standard sperm processing techniques employed in assisted reproduction programs include simple washing, swim-up, migration and sedimentation, glass wool filtration, and density-gradient centrifugation (DGC). For the latter, different kinds of gradients such as PureSperm ${ }^{\circ}$, Percoll ${ }^{\circ}$ gradients that produce varying results are used. The specific advantages and disadvantages have been reviewed [84]. Other more sophisticated and more recently developed techniques are annexin $\mathrm{V}$ magnetic activated cell separation which is based on the externalization of phosphatidylserine [91], hyaluronic acid- (HA-) mediated sperm selection based on the presence of HA receptors [92], electrophoretic isolation [93, 94], and the zeta method, which is based on sperm membrane electric charge [95].

With respect to finding the most appropriate method to employ in order to obtain a normal functional sperm (i.e., without damage), several studies had been conducted with no consensus reached as to which method between densitygradient centrifugation and swim-up method can be recommended [96-99]. The use of apoptotic or DNA-damaged sperm during assisted reproductive techniques (ARTs) has been linked to be one reason for suboptimal fertilization results. Particularly in cases with extremely poor semen quality, when intracytoplasmic sperm injection (ICSI) needs to be performed to achieve fertilization, the demand for the sperm separation technique lies in selecting not only the most motile spermatozoa, but also the most competent ones. The problem is that functional competence of individual sperm cells including the quality of chromatin condensation and DNA integrity cannot be assessed using normal light microscopy without using individual spermatozoa for the test. Therefore, scientists tried to find physiologic associations 
between visible features and the DNA quality and relate these associations to sperm separation.

Ricci et al. [100] aimed to compare the effects of densitygradient centrifugation and swim-up methods on sperm quality by the use of multiparameter flow cytometry. Their findings indicate that DGC significantly increased the mean recovery rate of viable sperm ("quantity"), while swim-up significantly lowered the mean percentage of apoptotic and necrotic sperm ("quality"). Furthermore, these authors also suggested that both preparatory methods led to obtaining a sperm population with a low percentage of apoptotic sperm. Considering the unavailability of flow cytometry in most ART laboratories, the choice of method of sperm preparation will depend on whether the sperm will be used for IUI or IVF/ICSI techniques [100].

Another study showed that fresh and washed semen samples had the highest levels of sperm DNA fragmentation compared to swim-up, DGC, and DGC followed by a swim-up, with the latter having the most significant effect [85]. On the other hand, other authors demonstrated that elimination of apoptotic-like spermatozoa from semen is not very effective after DGC [101-103]. DGC and the swim-up technique have different efficiencies in removing single- or double-stranded DNA breaks [104], of which the former is quite effective in isolating spermatozoa with singular characteristics such as large size telomere [105].

In a different study, DGC brought about a significant reduction in the baseline level of sperm DNA fragmentation but is deleterious to the sperm DNA longevity after freezing and thawing in comparison to neat semen samples [106]. Hence, these authors proposed a direct sperm wash using a standard semen extender and direct sperm isolation using polyvinyl pyrrolidone (PVP), thereby avoiding centrifugation. This principle was first described by Shekarriz et al. [107] who showed that centrifugation time is an essential factor that causes sublethal damage to spermatozoa due to oxidative stress.

Translocation of phosphatidylserine (PS) from the inner to the outer leaflet of the plasma membrane takes place during early stages of apoptosis [108]. Considering that annexin V has a high affinity for PS and binds to externalized PS, this test serves as an early marker of apoptosis [109]. According to Hoogendijk et al. [102] the use of fluorescing conjugate annexin $\mathrm{V}$ and flow cytometry with a strict sperm morphology assessment is a noninvasive method that can be effectively used to separate annexin $\mathrm{V}$-negative and $\mathrm{V}$-positive sperm subpopulations. These findings also suggested that annexin V-negative spermatozoa have a morphologically superior quality compared to the annexin V-positive subpopulation [102].

Bungum et al. [110] recommended that sperm DNA analysis by means of the SCSA should be performed on raw semen aliquots, as elevated DFI identified in neat semen may reflect chromatin abnormalities within an entire sperm population and are not completely eliminated by density-gradient centrifugation or swim-up [111]. Hence, the DFI in neat semen is regarded as predictive of the treatment outcome of ART whereas the determination of this parameter in DGC samples would not be predictive of pregnancy outcome [18, 110-112].
Similar to Jackson et al. [85], Toro and coworkers [113] showed a significant increase in DFI in samples incubated for 2-4 hours at room temperature in comparison to nonincubated (fresh) semen samples. The implication of this finding for ART is that the DFI can be higher in processed semen samples, that is, incubated at room temperature or cryopreserved. In addition, in a fixed aliquot used for DNA fragmentation testing before insemination the DNA damage as determined by means of the SCSA can be different from that in the sample directly used for oocyte insemination [113]. Hence, unnecessary incubation of semen in the laboratory should be avoided, as increased sperm DNA fragmentation was observed during aerobic incubation of semen and after semen cryopreservation [113].

Since the 1960s, cryopreservation of human spermatozoa has been a routine practice in many assisted reproductive technology laboratories [114] and has become an integral part of ARTs [115]. However, this technique poses the risk of oxidative stress with increased apoptotic DNA fragmentation regardless of the sperm concentration, yet the percentage of DNA-damaged sperm is higher in oligozoospermic men [116]. It appears that particularly the thawing process of cryopreserved sperm results in increased oxygen radical induced damage that leads to sperm DNA fragmentation [113]. These effects of ROS on DNA integrity include abasic sites, crosslinking, modification of nitrogenous bases, and DNA strand breakages $[117,118]$.

Repeated freezing and thawing cycles are usually offered to patients in order to maximize the use of the available sperm for reasons that may include maximizing the usage of samples obtained for cryopreservation before the treatment of cancer or other diseases, from patients with severe oligozoospermia or intermittent azoospermia, sexual dysfunction, or for the purpose of cost-effectiveness [119]. Several studies have demonstrated the detrimental effects of repeated cycles of freezing and thawing to not only decrease the percentage of motile and viable sperm but also increase the percentage of sperm with DNA damage [120-122]. On the other hand, repeated freezing and thawing up to three cycles produced similar level of risk with respect to sperm DNA damage in comparison to a single cycle, provided the samples are refrozen in their original cryoprotectant and not washed or have undergone any further treatment and are separated by DGC or swim-up before use in ART [119].

Most of the studies employed to test for DNA integrity are testing either potential (e.g., SCSA) or real (e.g., TUNEL assay) DNA fragmentation, with the relevant advantages or disadvantages [4]. Even though in the absence of fragmentation, significant DNA damage could still be detected in some genome regions [123]. In order to use a molecularly healthy semen sample for insemination, Valcarce et al. [124] recommended a quantitative PCR- (qPCR-) base technique that can be used for DNA evaluation in specific genes (PRM1, BIK, FSHB, PEG1/MEST, ADD1, ARNT, UBE3A, and SNORD116/ PWSAS) that could assist in selecting and improving cryopreservation protocols used in clinics [124]. In order to investigate and compare commercially available cryoprotectant media in terms of DNA integrity of spermatozoa recovered after cryopreservation and separation using DGC, Thomson 
et al. [122] found no significant difference between each type of cryoprotectant to preserve DNA integrity or in its ability to predict the percentage of fragmented DNA after cryopreservation, thawing, and DGC.

Finally, considering that the current most frequently used sperm separation methods swim-up and density-gradient centrifugation are essentially limited in their selection of the most functionally competent spermatozoa, particularly in cases of poor and very poor semen quality, new procedures that could safely and efficiently select motile sperm are desirable [125] and are either in practical use such as motile sperm organelle morphological examination (MSOME) which, in combination with ICSI (IMSI) or after HA-binding (PICSI), showed ability to select functionally competent spermatozoa or in an experimental stage such as Raman spectrometry [126] or polarization microscopy [127] (for review see [5]). In the context of applying physiological criteria for the sperm selection, chemotaxis, thermotaxis, and probable oviductal contraction are also thought to be some of the physiologic mechanisms that successfully guide the sperm along the female genital tract [128]. A microchannel-based device that mimics the mammalian female reproductive tract and allows for both motility screening and chemotaxis testing simultaneously resulted in the selection of competent spermatozoa which could possibly be used for IVF to improve fertilization and pregnancy rates [125].

\section{Effects of Lifestyle}

The reproductive system has evolved over millions of years. Yet the human is unique as we are severely and rapidly not only changing our own environment, but also changing our behaviour and habits in a negative way. In addition, human spermatogenesis appears to be genetically impaired as compared to other animal species [129] and a number of mutations in fertility genes considered important in other species are evident $[130,131]$ and apparently make the human species essentially subfertile and more susceptible to negative environmental influences [129].

Among the lifestyle factors negatively influencing are cigarette smoking, drugs, alcohol abuse, heat exposure, or obesity. The common feature of the exposure of a man's body to these factors is the significant increase of reactive oxygen species causing oxidative stress leading to infertility as well as having significant effect on the offspring. Significant associations exist between paternal smoking and increased sperm DNA damage and elevated levels of 8-hydroxy-2' -deoxyguanosine (8-OHdG) $[132,133]$ caused by the high cadmium content of cigarette smoke which is known to trigger and promote DNA damage [133-135]. The DNA damage is further exacerbated by the presence of Ser326Cys polymorphism in the 8-oxoguanine DNA glycosylase 1 (OGG1) gene [136]. OGG1 is downregulated by cadmium [137]. In addition, paternal, but not maternal, cigarette smoking is positively associated with an increased risk of early childhood cancer in the progeny $[9,138,139]$. Moreover, the risk of oxidative damage to sperm in smokers is even higher as this habit causes a $48 \%$ increase in seminal leukocyte concentration and ROS [140] as well as a decrease in antioxidant levels $[132,141]$.
Alcohol has also been described as a potent systemic stimulator of ROS $[142,143]$, which would then contribute to seminal oxidative stress. These studies also reveal that alcoholic men often suffer from a lack of antioxidative defence due to insufficient diets, a fact which in turn worsens the situation. Maneesh et al. [144] reported that alcoholic men had significantly reduced plasma testosterone concentrations confirming the disturbances in the hypothalamus-pituitarygonadal axis [145]. It also seems that chronic alcohol abuse leads to a higher risk of XY chromosome aneuploidy as compared to nondrinkers [146].

Another parameter that is significantly changed as a result of our modern lifestyle is testicular temperature. The rationale behind this thermosensitivity is that in most mammalian species, including man, the testicles are located extracorporally in the scrotum resulting in scrotal temperatures of about $34^{\circ} \mathrm{C}-35^{\circ} \mathrm{C}$. In addition, it is notable that the scrotal skin has very little hairs and numerous sweat glands, which ensure that the evaporating moist is cooling down the scrotum including the testicles. Moreover, the pampiniform plexus represents an effective heat exchanger by means of a counterflow mechanism which cools down the arterial blood inflow into the testes (for review see $[147,148]$ ). These mechanisms, together with the actions of the dartos and cremaster muscles, lead to effective testicular thermoregulation (for review see [149]). It is thought that lower scrotal temperatures reduce oxidative damage to the sperm DNA and lower the metabolic rate in the epididymis leading to less mutations and therefore to less oxidative stress, respectively $[147,150,151]$. Numerous studies revealed that both Sertoli cells and the process of spermatogenesis per se are sensitive to elevated temperatures, particularly the steps of the transition from gonocytes to spermatogonia $A_{\text {dark }}$, as well as from primary to secondary spermatocytes [152-154].

The fact that many people have jobs with sedentary positions such as office workers and taxi or long-distance drivers or many men are occupationally exposed to high temperatures, for example, in the welding or metal manufacturing industry or in bakeries, and, also, regular wet heat exposure of the testicles in Jacuzzis, saunas, or hot baths can have a significant negative effect on semen quality [155]. The latter exposure appears to be reversible as studies of Jung et al. [156, 157] have shown that nocturnal scrotal cooling can improve semen quality. Well-known pathologies which lead to elevated testicular temperatures are cryptorchidism and varicocele of which both conditions have been shown to be a cause of sperm DNA fragmentation due to induction of apoptosis with subsequent consequences for the developing embryo $[158,159]$.

Last but not least, overweight, obesity, and metabolic syndrome not only are increasing problems worldwide contributing to the overall burden of other chronic illnesses and causing major conditions such as cardiovascular diseases, but also significantly affect male fertility via various possible mechanisms. Particularly, obesity and the metabolic syndrome are considered to cause a systemic inflammatory condition with increased levels of C-reactive protein and inflammatory cytokines [160] and ROS [161]. Several authors [162165] could demonstrate the significant negative effect of 
obesity on sperm count, motility, and function. Significant differences between metabolic syndrome patients and normal fertile donors were found not only for sperm motility or DNA fragmentation, but also for serum and seminal inflammatory cytokines such as TNF $\alpha$, IL-1 $\beta$, IL-6, and IL- 8 with values being significantly higher in seminal plasma (Leisegang et al., unpublished). Thus, it appears that these inflammatory cytokines per se stimulate lipid peroxidation [166, 167], a process which is triggered and propagated by ROS [168], and in turn cause DNA damage. On the other hand, according to a recent small study including six obese men by Faure et al. [169], it appears that obesity is a correctable lifestyle factor as significant loss of abdominal fat through a lifestyle program led to significantly decreased sperm DNA fragmentation, increased serum testosterone levels, decreased seminal oxidative stress by increased superoxide dismutase levels, and, most importantly, pregnancy in all spouses included in the study.

\section{Conclusion}

Since human lifestyle and behaviour and environmental pollution significantly affect male reproductive functions including the fertilizing ability of spermatozoa, more and more couples are suffering from male infertility posing an increasing global problem. As a result, assisted reproductive techniques had been developed in which scientists and clinicians try to select the most competent spermatozoa to be used for the fertilization process. However, all these efforts are only dealing with the symptoms and consequences of the problem as many of the factors causing oxidative stress to the male germ cells are modifiable either by avoidance of exposure to environmental toxicants or by behavioural changes (e.g., stopping smoking and drinking, wearing loose underpants) or by loss of weight and following a healthy diet [170]. Alternatively, oxidative stress can be reduced by taking clinically formulated antioxidant supplements which if correctly administered to the patient can improve the success rate of reproduction. Yet uncontrolled intake of the so-called healthy supplements can also cause harm and significant adverse effects $[35,44,171]$. Therefore, a complete evaluation, not only of the individual patient, but also of the sperm nucleus quality, should be mandatory [172].

\section{Conflict of Interests}

The authors declare that there is no conflict of interests regarding the publication of this paper.

\section{References}

[1] R. Henkel, "Sperm processing for IVF", in Practical Manual of in Vitro Fertilization: Advanced Methods and Novel Devices, Z. P. Nagy, A. C. Varghese, and A. Agarwal, Eds., pp. 13-24, Springer, 2012.

[2] R. A. Saleh, A. Agarwal, E. A. Nada et al., "Negative effects of increased sperm DNA damage in relation to seminal oxidative stress in men with idiopathic and male factor infertility," Fertility and Sterility, vol. 79, no. 3, pp. 1597-1605, 2003.
[3] J. Erenpreiss, S. Elzanaty, and A. Giwercman, "Sperm DNA damage in men from infertile couples," Asian Journal of Andrology, vol. 10, no. 5, pp. 786-790, 2008.

[4] R. Henkel, "DNA based sperm assessment," in Advances in Fertility Studies and Reproductive Medicine, IFFS 2007, T. F. Kruger, Z. van der Spuy, and R. D. Kempers, Eds., pp. 284-292, Juta, Cape Town, South Africa, 2007.

[5] R. Henkel, "Sperm preparation: state-of-the-physiological aspects and application of advanced sperm preparation methods," Asian Journal of Andrology, vol. 14, no. 2, pp. 260-269, 2012.

[6] R. Henkel, "Novel sperm tests and their importance," in NonInvasive Sperm Selection for In Vitro Fertilization, A. Agarwal, E. Borges Jr., and A. S. Setti, Eds., pp. 23-40, Springer, New York, NY, USA, 2015.

[7] D. Gavriliouk and R. J. Aitken, "Damage to sperm DNA mediated by reactive oxygen species: its impact on human reproduction and the health trajectory of offspring," Advances in Experimental Medicine and Biology, vol. 868, pp. 23-47, 2015.

[8] R. J. Aitken, E. Gordon, D. Harkiss et al., "Relative impact of oxidative stress on the functional competence and genomic integrity of human spermatozoa," Biology of Reproduction, vol. 59, no. 5, pp. 1037-1046, 1998.

[9] B.-T. Ji, X.-O. Shu, M. S. Linet et al., "Paternal cigarette smoking and the risk of childhood cancer among offspring of nonsmoking mothers," Journal of the National Cancer Institute, vol. 89, no. 3, pp. 238-244, 1997.

[10] J. J. Kurinczuk and C. Bower, "Birth defects in infants conceived by intracytoplasmic sperm injection: an alternative interpretation," British Medical Journal, vol. 315, no. 7118, pp. 1260-1266, 1997.

[11] R. J. Aitken and C. Krausz, "Oxidative stress, DNA damage and the Y chromosome," Reproduction, vol. 122, no. 4, pp. 497-506, 2001.

[12] R. J. Aitken and D. Sawyer, "The human spermatozoon-not waving but drowning," Advances in Experimental Medicine and Biology, vol. 518, pp. 85-98, 2003.

[13] J. J. Kurinczuk, M. Hansen, and C. Bower, "The risk of birth defects in children born after assisted reproductive technologies," Current Opinion in Obstetrics and Gynecology, vol. 16, no. 3, pp. 201-209, 2004.

[14] M. Hansen, C. Bower, E. Milne, N. de Klerk, and J. J. Kurinczuk, "Assisted reproductive technologies and the risk of birth defects-a systematic review," Human Reproduction, vol. 20, no. 2, pp. 328-338, 2005.

[15] L. Robinson, I. D. Gallos, S. J. Conner et al., “The effect of sperm DNA fragmentation on miscarriage rates: a systematic review and meta-analysis," Human Reproduction, vol. 27, no. 10, pp. 2908-2917, 2012.

[16] L. Simon, I. Proutski, M. Stevenson et al., "Sperm DNA damage has a negative association with live-birth rates after IVF," Reproductive BioMedicine Online, vol. 26, no. 1, pp. 68-78, 2013.

[17] Z. Li, L. Wang, J. Cai, and H. Huang, "Correlation of sperm DNA damage with IVF and ICSI outcomes: a systematic review and meta-analysis," Journal of Assisted Reproduction and Genetics, vol. 23, no. 9-10, pp. 367-376, 2006.

[18] M. Bungum, P. Humaidan, A. Axmon et al., "Sperm DNA integrity assessment in prediction of assisted reproduction technology outcome," Human Reproduction, vol. 22, no. 1, pp. 174179, 2007. 
[19] A. Zini, K. Kamal, D. Phang, J. Willis, and K. Jarvi, "Biologic variability of sperm DNA denaturation in infertile men," Urology, vol. 58, no. 2, pp. 258-261, 2001.

[20] R. Henkel, E. Kierspel, T. Stalf et al., "Effect of reactive oxygen species produced by spermatozoa and leukocytes on sperm functions in non-leukocytospermic patients," Fertility and Sterility, vol. 83, no. 3, pp. 635-642, 2005.

[21] S. E. M. Lewis, R. J. Aitken, S. J. Conner et al., "The impact of sperm DNA damage in assisted conception and beyond: recent advances in diagnosis and treatment," Reproductive BioMedicine Online, vol. 27, no. 4, pp. 325-337, 2013.

[22] S. E. M. Lewis, "Sperm DNA fragmentation and base oxidation," Advances in Experimental Medicine and Biology, vol. 791, pp. 103-116, 2014.

[23] F. M. Helmerhorst, D. A. M. Perquin, D. Donker, and M. J. N. C. Keirse, "Perinatal outcome of singletons and twins after assisted conception: a systematic review of controlled studies," British Medical Journal, vol. 328, no. 7434, pp. 261-264, 2004.

[24] A. A. Rimm, A. C. Katayama, M. Diaz, and K. P. Katayama, "A meta-analysis of controlled studies comparing major malformation rates in IVF and ICSI infants with naturally conceived children," Journal of Assisted Reproduction and Genetics, vol. 21, no. 12, pp. 437-443, 2004.

[25] N. Zwink, E. Jenetzky, E. Schmiedeke et al., "Assisted reproductive techniques and the risk of anorectal malformations: a German case-control study," Orphanet Journal of Rare Diseases, vol. 7, no. 1, article 65, 2012.

[26] N. Whitelaw, S. Bhattacharya, G. Hoad, G. W. Horgan, M. Hamilton, and P. Haggarty, "Epigenetic status in the offspring of spontaneous and assisted conception," Human Reproduction, vol. 29, no. 7, pp. 1452-1458, 2014.

[27] L. Simon, K. Murphy, M. B. Shamsi et al., "Paternal influence of sperm DNA integrity on early embryonic development," Human Reproduction, vol. 29, no. 11, pp. 2402-2412, 2014.

[28] V. Burruel, K. Klooster, C. M. Barker, R. R. Pera, and S. Meyers, "Abnormal early cleavage events predict early embryo demise: sperm oxidative stress and early abnormal cleavage," Scientific Reports, vol. 4, article 6598, 2014.

[29] L. R. Ghaleno, M. R. Valojerdi, F. Hassani, M. Chehrazi, and E. Janzamin, "High level of intracellular sperm oxidative stress negatively influences embryo pronuclear formation after intracytoplasmic sperm injection treatment," Andrologia, vol. 46, no. 10, pp. 1118-1127, 2014.

[30] M. Hyrapetian, E. M. Loucaides, and A. G. Sutcliffe, "Health and disease in children born after Assistive Reproductive Therapies (ART)," Journal of Reproductive Immunology, vol. 106, pp. 21-26, 2014.

[31] F. Parazzini, S. Cipriani, G. Bulfoni et al., "The risk of birth defects after assisted reproduction," Journal of Assisted Reproduction and Genetics, vol. 32, no. 3, pp. 379-385, 2015.

[32] R. Mendoza, S. Perez, M. J. de Los Santos et al., "Congenital malformations, chromosomal abnormalities and perinatal results in IVF/ICSI newborns resulting from very poor quality embryos: a case-control study," Gynecologic and Obstetric Investigation, vol. 79, no. 2, pp. 83-89, 2015.

[33] J. L. Simpson, "Birth defects and assisted reproductive technologies," Seminars in Fetal and Neonatal Medicine, vol. 19, no. 3, pp. 177-182, 2014.

[34] R. Henkel, C. F. Hoogendijk, P. J. D. Bouic, and T. F. Kruger, "TUNEL assay and SCSA determine different aspects of sperm DNA damage," Andrologia, vol. 42, no. 5, pp. 305-313, 2010.
[35] R. R. Henkel, "Leukocytes and oxidative stress: dilemma for sperm function and male fertility," Asian Journal of Andrology, vol. 13, no. 1, pp. 43-52, 2011.

[36] R. Henkel, "ROS and semen quality," in Studies on Men's Health and Fertility, A. Agarwal, R. J. Aitken, and J. Alvarez, Eds., pp. 301-323, Humana Press, New York, NY, USA, 2012.

[37] A. Agarwal, G. Virk, C. Ong, and S. S. du Plessis, "Effect of oxidative stress on male reproduction," The World Journal of Men's Health, vol. 32, no. 1, pp. 1-17, 2014.

[38] R. J. Aitken, Z. Gibb, M. A. Baker et al., "Causes and consequences of oxidative stress in spermatozoa," Reproduction, Fertility and Development, vol. 28, no. 2, pp. 1-10, 2016.

[39] R. J. Aitken, J. S. Clarkson, and S. Fishel, "Generation of reactive oxygen species, lipid peroxidation, and human sperm function," Biology of Reproduction, vol. 41, no. 1, pp. 183-197, 1989.

[40] E. de Lamirande and C. Gagnon, "A positive role for the superoxide anion in triggering hyperactivation and capacitation of human spermatozoa," International Journal of Andrology, vol. 16, no. 1, pp. 21-25, 1993.

[41] S. Lopes, A. Jurisicova, J.-G. Sun, and R. F. Casper, "Reactive oxygen species: potential cause for DNA fragmentation in human spermatozoa," Human Reproduction, vol. 13, no. 4, pp. 896-900, 1998.

[42] H. Sies and H. de Groot, "Role of reactive oxygen species in cell toxicity," Toxicology Letters, vol. 64-65, pp. 547-551, 1992.

[43] E. de Lamirande and C. Gagnon, "Impact of reactive oxygen species on spermatozoa: a balancing act between beneficial and detrimental effects," Human Reproduction, vol. 10, no. 1, pp. 1521, 1995.

[44] J. M. C. Gutteridge and B. Halliwell, "Antioxidants: molecules, medicines, and myths," Biochemical and Biophysical Research Communications, vol. 393, no. 4, pp. 561-564, 2010.

[45] S. Kothari, A. Thompson, A. Agarwal, and S. S. du Plessis, "Free radicals: their beneficial and detrimental effects on sperm function," Indian Journal of Experimental Biology, vol. 48, no. 5, pp. 425-435, 2010.

[46] C. Ufer, C. C. Wang, A. Borchert, D. Heydeck, and H. Kuhn, "Redox control in mammalian embryo development," Antioxidants and Redox Signaling, vol. 13, no. 6, pp. 833-875, 2010.

[47] T. Suzuki, N. Sugino, T. Fukaya et al., "Superoxide dismutase in normal cycling human ovaries: immunohistochemical localization and characterization," Fertility and Sterility, vol. 72, no. 4, pp. 720-726, 1999.

[48] N. B. Karuputhula, R. Chattopadhyay, B. Chakravarty, and K. Chaudhury, "Oxidative status in granulosa cells of infertile women undergoing IVF,' Systems Biology in Reproductive Medicine, vol. 59, no. 2, pp. 91-98, 2013.

[49] D. A. Dumesic, D. R. Meldrum, M. G. Katz-Jaffe, R. L. Krisher, and W. B. Schoolcraft, "Oocyte environment: follicular fluid and cumulus cells are critical for oocyte health," Fertility and Sterility, vol. 103, no. 2, pp. 303-316, 2015.

[50] S. E. Elizur, O. Lebovitz, R. Orvieto, J. Dor, and T. ZanBar, "Reactive oxygen species in follicular fluid may serve as biochemical markers to determine ovarian aging and follicular metabolic age," Gynecological Endocrinology, vol. 30, no. 10, pp. 705-707, 2014.

[51] O. Oyawoye, A. A. Gadir, A. Garner, N. Constantinovici, C. Perrett, and P. Hardiman, "Antioxidants and reactive oxygen species in follicular fluid of women undergoing IVF: relationship to outcome," Human Reproduction, vol. 18, no. 11, pp. 22702274, 2003. 
[52] M. A. Bedaiwy, S. A. Elnashar, J. M. Goldberg et al., "Effect of follicular fluid oxidative stress parameters on intracytoplasmic sperm injection outcome," Gynecological Endocrinology, vol. 28, no. 1, pp. 51-55, 2012.

[53] A. K. Seleem, A. A. El Refaeey, D. Shaalan, Y. Sherbiny, and A. Badawy, "Superoxide dismutase in polycystic ovary syndrome patients undergoing intracytoplasmic sperm injection," Journal of Assisted Reproduction and Genetics, vol. 31, no. 4, pp. 499-504, 2014.

[54] H. R. Behrman, P. H. Kodaman, S. L. Preston, and S. Gao, "Oxidative stress and the ovary," Journal of the Society for Gynecologic Investigation, vol. 8, no. 1, pp. S40-S42, 2001.

[55] P. J. Devine, S. D. Perreault, and U. Luderer, "Roles of reactive oxygen species and antioxidants in ovarian toxicity," Biology of Reproduction, vol. 86, no. 2, article 27, 2012.

[56] H. I. Calvin, K. Grosshans, and E. J. Blake, "Estimation and manipulation of glutathione levels in prepuberal mouse ovaries and ova: relevance to sperm nucleus transformation in the fertilized egg," Gamete Research, vol. 14, no. 3, pp. 265-275, 1986.

[57] S. D. Perreault, R. R. Barbee, and V. L. Slott, "Importance of glutathione in the acquisition and maintenance of sperm nuclear decondensing activity in maturing hamster oocytes," Developmental Biology, vol. 125, no. 1, pp. 181-186, 1988.

[58] P. Sutovsky and G. Schatten, "Depletion of glutathione during bovine oocyte maturation reversibly blocks the decondensation of the male pronucleus and pronuclear apposition during fertilization," Biology of Reproduction, vol. 56, no. 6, pp. 15031512, 1997.

[59] S. D. Perreault, R. A. Wolff, and B. R. Zirkin, "The role of disulfide bond reduction during mammalian sperm nuclear decondensation in vivo," Developmental Biology, vol. 101, no. 1, pp. 160-167, 1984.

[60] M. Vega, I. Carrasco, T. Castillo, J. L. Troncoso, L. A. Videla, and L. Devoto, "Functional luteolysis in response to hydrogen peroxide in human luteal cells," Journal of Endocrinology, vol. 147, no. 1, pp. 177-182, 1995.

[61] A. Agarwal, S. Gupta, and R. K. Sharma, "Role of oxidative stress in female reproduction," Reproductive Biology and Endocrinology, vol. 3, article 28, 2005.

[62] S. M. G. McPherson and F. J. Longo, "Localization of DNase Ihypersensitive regions during rat spermatogenesis: stage dependent patterns and unique sensitivity of elongating spermatids," Molecular Reproduction and Development, vol. 31, no. 4, pp. 268-279, 1992.

[63] E. Gomez, D. W. Buckingham, J. Brindle, F. Lanzafame, D. S. Irvine, and R. J. Aitken, "Development of an Image analysis system to monitor the retention of residual cytoplasm by human spermatozoa: correlation with biochemical markers of the cytoplasmic space, oxidative stress, and sperm function," Journal of Andrology, vol. 17, no. 3, pp. 276-287, 1996.

[64] D. Sakkas, E. Mariethoz, G. Manicardi, D. Bizzaro, P. G. Bianchi, and U. Bianchi, "Origin of DNA damage in ejaculated human spermatozoa," Reviews of Reproduction, vol. 4, no. 1, pp. 31-37, 1999.

[65] R. Henkel, M. Hajimohammad, T. Stalf et al., "Influence of deoxyribonucleic acid damage on fertilization and pregnancy," Fertility and Sterility, vol. 81, no. 4, pp. 965-972, 2004.

[66] J. G. Alvarez, "The predictive value of sperm chromatin structure assay," Human Reproduction, vol. 20, no. 8, pp. 2365-2367, 2005.

[67] A. J. Koppers, G. N. De Iuliis, J. M. Finnie, E. A. McLaughlin, and R. J. Aitken, "Significance of mitochondrial reactive oxygen species in the generation of oxidative stress in spermatozoa," Journal of Clinical Endocrinology and Metabolism, vol. 93, no. 8, pp. 3199-3207, 2008.

[68] J. G. Alvarez, J. L. Lasso, L. Blasco et al., "Centrifugation of human spermatozoa induces sublethal damage; separation of human spermatozoa from seminal plasma by a dextran swimup procedure without centrifugation extends their motile lifetime," Human Reproduction, vol. 8, no. 7, pp. 1087-1092, 1993.

[69] A. Agarwal, I. Ikemoto, and K. R. Loughlin, "Effect of sperm washing on levels of reactive oxygen species in semen," Archives of Andrology, vol. 33, no. 3, pp. 157-162, 1994.

[70] C.-S. Chen, H.-T. Chao, R.-L. Pan, and Y.-H. Wei, "Hydroxyl radical-induced decline in motility and increase in lipid peroxidation and DNA modification in human sperm," Biochemistry and Molecular Biology International, vol. 43, no. 2, pp. 291-303, 1997.

[71] R. Moazamian, A. Polhemus, H. Connaughton et al., "Oxidative stress and human spermatozoa: diagnostic and functional significance of aldehydes generated as a result of lipid peroxidation," Molecular Human Reproduction, vol. 21, no. 6, pp. 502515, 2015.

[72] P. C. Burcham, "Genotoxic lipid peroxidation products: their DNA damaging properties and role in formation of endogenous DNA adducts," Mutagenesis, vol. 13, no. 3, pp. 287-305, 1998.

[73] L. J. Marnett, "Lipid peroxidation-DNA damage by malondialdehyde," Mutation Research/Fundamental and Molecular Mechanisms of Mutagenesis, vol. 424, no. 1-2, pp. 83-95, 1999.

[74] L. J. Marnett, "Oxy radicals, lipid peroxidation and DNA damage," Toxicology, vol. 181-182, pp. 219-222, 2002.

[75] V. Peltola, E. Mäntylä, I. Huhtaniemi, and M. Ahotupa, "Lipid peroxidation and antioxidant enzyme activities in the rat testis after cigarette smoke inhalation or administration of polychlorinated biphenyls or polychlorinated naphthalenes," Journal of Andrology, vol. 15, no. 4, pp. 353-361, 1994.

[76] T. Kasai, K. Ogawa, K. Mizuno et al., "Relationship between sperm mitochondrial membrane potential, sperm motility, and fertility potential," Asian Journal of Andrology, vol. 4, no. 2, pp. 97-103, 2002.

[77] C. Marchetti, G. Obert, A. Deffosez, P. Formstecher, and P. Marchetti, "Study of mitochondrial membrane potential, reactive oxygen species, DNA fragmentation and cell viability by flow cytometry in human sperm," Human Reproduction, vol. 17, no. 5, pp. 1257-1265, 2002.

[78] M. J. Tomlinson, C. L. R. Barratt, and I. D. Cooke, "Prospective study of leukocytes and leukocyte subpopulations in semen suggests they are not a cause of male infertility," Fertility and Sterility, vol. 60, no. 6, pp. 1069-1075, 1993.

[79] W. C. L. Ford, “The role of oxygen free radicals in the pathology of human spermatozoa: implications of IVF," in Clinical IVF Forum; Current Views in Assisted Reproduction, P. L. Matson and B. A. Lieberman, Eds., pp. 123-139, Manchester University Press, Manchester, UK, 1990.

[80] E. de Lamirande and C. Gagnon, "Capacitation-associated production of superoxide anion by human spermatozoa," Free Radical Biology and Medicine, vol. 18, no. 3, pp. 487-495, 1995.

[81] D. Mortimer, "Sperm preparation techniques and iatrogenic failures of in vitro fertilization," Human Reproduction, vol. 6, no. 2, pp. 173-177, 1991.

[82] R. Yanagimachi and A. Bhattacharyya, "Acrosome-reacted guinea pig spermatozoa become fusion competent in the presence of extracellular potassium ions," Journal of Experimental Zoology, vol. 248, no. 3, pp. 354-360, 1988. 
[83] R. A. P. Harrison, "Capacitation mechanisms, and the role of capacitation as seen in eutherian mammals," Reproduction, Fertility and Development, vol. 8, no. 4, pp. 581-594, 1996.

[84] R. R. Henkel and W.-B. Schill, "Sperm preparation for ART," Reproductive Biology and Endocrinology, vol. 1, article 108, 2003.

[85] R. E. Jackson, C. L. Bormann, P. A. Hassun et al., "Effects of semen storage and separation techniques on sperm DNA fragmentation," Fertility and Sterility, vol. 94, no. 7, pp. 2626-2630, 2010.

[86] H. C. Ha, N. S. Sirisoma, P. Kuppusamy, J. L. Zweier, P. M. Woster, and R. A. Casero Jr., "The natural polyamine spermine functions directly as a free radical scavenger," Proceedings of the National Academy of Sciences of the United States of America, vol. 95, no. 19, pp. 11140-11145, 1998.

[87] W. S. B. Yeung, K.-F. Lee, R. Koistinen et al., "Roles of glycodelin in modulating sperm function," Molecular and Cellular Endocrinology, vol. 250, no. 1-2, pp. 149-156, 2006.

[88] W. S. B. Yeung, K.-F. Lee, R. Koistinen, H. Koistinen, M. Seppälä, and P. C. N. Chiu, "Effects of glycodelins on functional competence of spermatozoa," Journal of Reproductive Immunology, vol. 83, no. 1-2, pp. 26-30, 2009.

[89] M. Mahadevan and G. Baker, "Assessment and preparation of semen for in vitro fertilization," in Clinical In Vitro Fertilization, C. Wood and A. Trounson, Eds., pp. 83-97, Springer, Berlin, Germany, 1984.

[90] M. Kheirollahi-Kouhestani, S. Razavi, M. Tavalaee et al., "Selection of sperm based on combined density gradient and Zeta method may improve ICSI outcome," Human Reproduction, vol. 24, no. 10, pp. 2409-2416, 2009.

[91] T. M. Said, A. Agarwal, S. Grunewald, M. Rasch, H.-J. Glander, and U. Paasch, "Evaluation of sperm recovery following annexin $\mathrm{V}$ magnetic-activated cell sorting separation," Reproductive BioMedicine Online, vol. 13, no. 3, pp. 336-339, 2006.

[92] M. H. Nasr-Esfahani, S. Razavi, A. A. Vahdati, F. Fathi, and M. Tavalaee, "Evaluation of sperm selection procedure based on hyaluronic acid binding ability on ICSI outcome," Journal of Assisted Reproduction and Genetics, vol. 25, no. 5, pp. 197-203, 2008.

[93] C. Ainsworth, B. Nixon, and R. J. Aitken, "Development of a novel electrophoretic system for the isolation of human spermatozoa," Human Reproduction, vol. 20, no. 8, pp. 2261-2270, 2005.

[94] S. D. Fleming, R. S. Ilad, A.-M. G. Griffin et al., "Prospective controlled trial of an electrophoretic method of sperm preparation for assisted reproduction: comparison with density gradient centrifugation," Human Reproduction, vol. 23, no. 12, pp. 2646-2651, 2008.

[95] P. J. Chan, J. D. Jacobson, J. U. Corselli, and W. C. Patton, “A simple Zeta method for sperm selection based on membrane charge," Fertility and Sterility, vol. 85, no. 2, pp. 481-486, 2006.

[96] M. Spanò, E. Cordelli, G. Leter, F. Lombardo, A. Lenzi, and L. Gandini, "Nuclear chromatin variations in human spermatozoa undergoing swim-up and cryopreservation evaluated by the flow cytometric sperm chromatin structure assay," Molecular Human Reproduction, vol. 5, no. 1, pp. 29-37, 1999.

[97] D. Sakkas, G. C. Manicardi, M. Tomlinson et al., "The use of two density gradient centrifugation techniques and the swimup method to separate spermatozoa with chromatin and nuclear DNA anomalies," Human Reproduction, vol. 15, no. 5, pp. 11121116, 2000.
[98] A. Zini, A. Finelli, D. Phang, and K. Jarvi, "Influence of semen processing technique on human sperm DNA integrity," Urology, vol. 56, no. 6, pp. 1081-1084, 2000.

[99] E. V. Younglai, D. Holt, P. Brown, A. Jurisicova, and R. F. Casper, "Sperm swim-up techniques and DNA fragmentation," Human Reproduction, vol. 16, no. 9, pp. 1950-1953, 2001.

[100] G. Ricci, S. Perticarari, R. Boscolo, M. Montico, S. Guaschino, and G. Presani, "Semen preparation methods and sperm apoptosis: swim-up versus gradient-density centrifugation technique," Fertility and Sterility, vol. 91, no. 2, pp. 632-638, 2009.

[101] T. M. Said, S. Grunewald, U. Paasch et al., "Advantage of combining magnetic cell separation with sperm preparation techniques," Reproductive BioMedicine Online, vol. 10, no. 6, pp. 740-746, 2005.

[102] C. F. Hoogendijk, T. F. Kruger, P. J. D. Bouic, and R. R. Henkel, “A novel approach for the selection of human sperm using annexin V-binding and flow cytometry," Fertility and Sterility, vol. 91, no. 4, pp. 1285-1292, 2009.

[103] J. Stevanato, R. P. Bertolla, V. Barradas, D. M. Spaine, A. P. Cedenho, and V. Ortiz, "Semen processing by density gradient centrifugation does not improve sperm apoptotic deoxyribonucleic acid fragmentation rates," Fertility and Sterility, vol. 90, no. 3, pp. 889-890, 2008.

[104] M. Enciso, M. Iglesias, I. Galán, J. Sarasa, A. Gosálvez, and J. Gosálvez, "The ability of sperm selection techniques to remove single-or double-strand DNA damage," Asian Journal of Andrology, vol. 13, no. 5, pp. 764-768, 2011.

[105] M. Tamayo, A. Mosquera, I. Rego, F. J. Blanco, J. Gosálvez, and J. L. Fernández, "Decreased length of telomeric DNA sequences and increased numerical chromosome aberrations in human osteoarthritic chondrocytes," Mutation Research/Fundamental and Molecular Mechanisms of Mutagenesis, vol. 708, no. 1-2, pp. 50-58, 2011.

[106] J. Gosálvez, S. Johnston, C. López-Fernández et al., “Sperm fractions obtained following density gradient centrifugation in human ejaculates show differences in sperm DNA longevity," Asian Pacific Journal of Reproduction, vol. 3, no. 2, pp. 116-120, 2014.

[107] M. Shekarriz, D. M. De Wire, A. J. Thomas Jr., and A. Agarwal, "A method of human semen centrifugation to minimize the iatrogenic sperm injuries caused by reactive oxygen species," European Urology, vol. 28, no. 1, pp. 31-35, 1995.

[108] I. Vermes, C. Haanen, H. Steffens-Nakken, and C. P. M. Reutellingsperger, "A novel assay for apoptosis: flow cytometric detection of phosphatidylserine expression on early apoptotic cells using fluorescein labelled Annexin V,' Journal of Immunological Methods, vol. 184, no. 1, pp. 39-51, 1995.

[109] W. L. Van Heerde, P. G. de Groot, and C. P. M. Reutelingsperger, "The complexity of the phospholipid binding protein annexin V," Thrombosis and Haemostasis, vol. 73, no. 2, pp. 172-179, 1995.

[110] M. Bungum, M. Spanò, P. Humaidan, P. Eleuteri, M. Rescia, and A. Giwercman, "Sperm chromatin structure assay parameters measured after density gradient centrifugation are not predictive for the outcome of ART,' Human Reproduction, vol. 23, no. 1, pp. 4-10, 2008.

[111] K. L. Larson, C. J. DeJonge, A. M. Barnes, L. K. Jost, and D. P. Evenson, "Sperm chromatin structure assay parameters as predictors of failed pregnancy following assisted reproductive techniques," Human Reproduction, vol. 15, no. 8, pp. 1717-1722, 2000 . 
[112] M. Bungum, P. Humaidan, M. Spanò, K. Jepson, L. Bungum, and A. Giwercman, "The predictive value of Sperm Chromatin Structure Assay (SCSA) parameters for the outcome of intrauterine insemination, IVF and ICSI," Human Reproduction, vol. 19, no. 6, pp. 1401-1408, 2004.

[113] E. Toro, S. Fernández, A. Colomar et al., "Processing of semen can result in increased sperm DNA fragmentation," Fertility and Sterility, vol. 92, no. 6, pp. 2109-2112, 2009.

[114] J. K. Sherman, "Synopsis of the use of frozen human semen since 1964: state of the art of human semen banking," Fertility and Sterility, vol. 24, no. 5, pp. 397-412, 1973.

[115] M. Di Santo, N. Tarozzi, M. Nadalini, and A. Borini, "Human sperm cryopreservation: update on techniques, effect on DNA integrity, and implications for ART," Advances in Urology, vol. 2012, Article ID 854837, 12 pages, 2012.

[116] T. S. de Paula, R. P. Bertolla, D. M. Spaine, M. A. Cunha, N. Schor, and A. P. Cedenho, "Effect of cryopreservation on sperm apoptotic deoxyribonucleic acid fragmentation in patients with oligozoospermia," Fertility and Sterility, vol. 86, no. 3, pp. 597600, 2006.

[117] H. C. Box, J. B. Dawidzik, and E. E. Budzinski, "Free radicalinduced double lesions in DNA," Free Radical Biology and Medicine, vol. 31, no. 7, pp. 856-868, 2001.

[118] J. Baumber, B. A. Ball, J. J. Linfor, and S. A. Meyers, "Reactive oxygen species and cryopreservation promote DNA fragmentation in equine spermatozoa," Journal of Andrology, vol. 24, no. 4, pp. 621-628, 2003.

[119] L. K. Thomson, S. D. Fleming, K. Barone, J.-A. Zieschang, and A. M. Clark, "The effect of repeated freezing and thawing on human sperm DNA fragmentation," Fertility and Sterility, vol. 93, no. 4, pp. 1147-1156, 2010.

[120] O. Rofeim, T. A. Brown, and B. R. Gilbert, "Effects of serial thawrefreeze cycles on human sperm motility and viability," Fertility and Sterility, vol. 75, no. 6, pp. 1242-1243, 2001.

[121] E. Bandularatne and A. Bongso, "Evaluation of human sperm function after repeated freezing and thawing," Journal of Andrology, vol. 23, no. 2, pp. 242-249, 2002.

[122] L. K. Thomson, S. D. Fleming, L. Schulke, K. Barone, J.-A. Zieschang, and A. M. Clark, "The DNA integrity of cryopreserved spermatozoa separated for use in assisted reproductive technology is unaffected by the type of cryoprotectant used but is related to the DNA integrity of the fresh separated preparation," Fertility and Sterility, vol. 92, no. 3, pp. 991-1001, 2009.

[123] M. F. Riesco and V. Robles, "Quantification of DNA damage by q-PCR in cryopreserved zebrafish Primordial Germ Cells," Journal of Applied Ichthyology, vol. 28, no. 6, pp. 925-929, 2012.

[124] D. G. Valcarce, F. Cartón-García, M. F. Riesco, M. P. Herráez, and V. Robles, "Analysis of DNA damage after human sperm cryopreservation in genes crucial for fertilization and early embryo development," Andrology, vol. 1, no. 5, pp. 723-730, 2013.

[125] L. Xie, R. Ma, C. Han et al., "Integration of sperm motility and chemotaxis screening with a microchannel-based device," Clinical Chemistry, vol. 56, no. 8, pp. 1270-1278, 2010.

[126] F. Liu, Y. Zhu, Y. Liu et al., "Real-time Raman microspectroscopy scanning of the single live sperm bound to human zona pellucida," Fertility and Sterility, vol. 99, no. 3, pp. 684-e4, 2013.

[127] L. Gianaroli, M. C. Magli, G. Collodel, E. Moretti, A. P. Ferraretti, and B. Baccetti, "Sperm head's birefringence: a new criterion for sperm selection," Fertility and Sterility, vol. 90, no. 1, pp. 104-112, 2008.

[128] M. Eisenbach and L. C. Giojalas, "Sperm guidance in mammals - an unpaved road to the egg," Nature Reviews Molecular Cell Biology, vol. 7, no. 4, pp. 276-285, 2006.

[129] R. Ivell, "Lifestyle impact and the biology of the human scrotum," Reproductive Biology and Endocrinology, vol. 5, article $15,2007$.

[130] J. A. Jury, J. Frayne, and L. Hall, "Sequence analysis of a variety of primate fertilin alpha genes: evidence for non-functional genes in the gorilla and man," Molecular Reproduction and Development, vol. 51, no. 1, pp. 92-97, 1998.

[131] R. Ivell, W. Pusch, M. Balvers, M. Valentin, N. Walther, and G. Weinbauer, "Progressive inactivation of the haploid expressed gene for the sperm-specific endozepine-like peptide (ELP) through primate evolution," Gene, vol. 255, no. 2, pp. 335-345, 2000.

[132] C. G. Fraga, P. A. Motchnik, A. J. Wyrobek, D. M. Rempel, and B. N. Ames, "Smoking and low antioxidant levels increase oxidative damage to sperm DNA," Mutation Research/Fundamental and Molecular Mechanisms of Mutagenesis, vol. 351, no. 2, pp. 199-203, 1996.

[133] H.-M. Shen, S.-E. Chia, Z.-Y. Ni, A.-L. New, B.-L. Lee, and C.N. Ong, "Detection of oxidative DNA damage in human sperm and the association with cigarette smoking," Reproductive Toxicology, vol. 11, no. 5, pp. 675-680, 1997.

[134] D.-X. Xu, H.-M. Shen, Q.-X. Zhu et al., “The associations among semen quality, oxidative DNA damage in human spermatozoa and concentrations of cadmium, lead and selenium in seminal plasma," Mutation Research, vol. 534, no. 1-2, pp. 155-163, 2003.

[135] H. Oliveira, M. Spanò, C. Santos, and M. D. L. Pereira, "Adverse effects of cadmium exposure on mouse sperm," Reproductive Toxicology, vol. 28, no. 4, pp. 550-555, 2009.

[136] G. Ji, L. Yan, W. Liu, J. Qu, and A. Gu, “OGG1 Ser326Cys polymorphism interacts with cigarette smoking to increase oxidative DNA damage in human sperm and the risk of male infertility," Toxicology Letters, vol. 218, no. 2, pp. 144-149, 2013.

[137] C.-K. Youn, S.-H. Kim, D. Y. Lee et al., "Cadmium downregulates human OGG1 through suppression of Spl activity," The Journal of Biological Chemistry, vol. 280, no. 26, pp. 25185-25195, 2005.

[138] T. Sorahan, P. Prior, R. J. Lancashire et al., "Childhood cancer and parental use of tobacco: deaths from 1971 to 1976," British Journal of Cancer, vol. 76, no. 11, pp. 1525-1531, 1997.

[139] K.-M. Lee, M. H. Ward, S. Han et al., "Paternal smoking, genetic polymorphisms in CYP1A1 and childhood leukemia risk," Leukemia Research, vol. 33, no. 2, pp. 250-258, 2009.

[140] R. A. Saleh, A. Agarwal, R. K. Sharma, D. R. Nelson, and A. J. Thomas Jr., "Effect of cigarette smoking on levels of seminal oxidative stress in infertile men: a prospective study," Fertility and Sterility, vol. 78, no. 3, pp. 491-499, 2002.

[141] T. Mostafa, G. Tawadrous, M. M. F. Roaia, M. K. Amer, R. A. Kader, and A. Aziz, "Effect of smoking on seminal plasma ascorbic acid in infertile and fertile males," Andrologia, vol. 38, no. 6, pp. 221-224, 2006.

[142] D. Wu and A. I. Cederbaum, "Alcohol, oxidative stress, and free radical damage," Alcohol Research and Health, vol. 27, no. 4, pp. 277-284, 2003.

[143] O. R. Koch, G. Pani, S. Borrello et al., "Oxidative stress and antioxidant defenses in ethanol-induced cell injury," Molecular Aspects of Medicine, vol. 25, no. 1-2, pp. 191-198, 2004. 
[144] M. Maneesh, S. Dutta, A. Chakrabarti, and D. M. Vasudevan, "Alcohol abuse-duration dependent decrease in plasma testosterone and antioxidants in males," Indian Journal of Physiology and Pharmacology, vol. 50, no. 3, pp. 291-296, 2006.

[145] T. W. Boyden and R. W. Pamenter, "Effects of ethanol on the male hypothalamic-pituitary-gonadal axis," Endocrine Reviews, vol. 4, no. 4, pp. 389-395, 1983.

[146] W. A. Robbins, D. A. Elashoff, L. Xun et al., "Effect of lifestyle exposures on sperm aneuploidy," Cytogenetic and Genome Research, vol. 111, no. 3-4, pp. 371-377, 2005.

[147] L. Werdelin and Å. Nilsonne, "The evolution of the scrotum and testicular descent in mammals: a phylogenetic view," Journal of Theoretical Biology, vol. 196, no. 1, pp. 61-72, 1999.

[148] B. P. Setchell, "The Parkes lecture. Heat and the testis," Journal of Reproduction and Fertility, vol. 114, no. 2, pp. 179-194, 1998.

[149] G. M. H. Waites, "Thermoregulation of the scrotum and testis: studies in animals and significance for man," Advances in Experimental Medicine and Biology, vol. 286, pp. 9-17, 1991.

[150] R. V. Short, "The testis: the witness of the mating system, the site of mutation and the engine of desire," Acta Paediatrica, vol. 86, supplement 422, pp. 3-7, 1997.

[151] S. Freeman, "The evolution of the scrotum: a new hypothesis," Journal of Theoretical Biology, vol. 145, no. 4, pp. 429-445, 1990.

[152] J. Kumagai, J. Fukuda, H. Kodama et al., "Germ cell-specific heat shock protein 105 binds to p53 in a temperature- sensitive manner in rat testis," European Journal of Biochemistry, vol. 267, no. 10, pp. 3073-3078, 2000.

[153] K. Hirai, H. Sasaki, H. Yamamoto et al., "HST-1/FGF-4 protects male germ cells from apoptosis under heat-stress condition," Experimental Cell Research, vol. 294, no. 1, pp. 77-85, 2004.

[154] X.-S. Zhang, Y.-H. Lue, S.-H. Guo et al., "Expression of Hsp105 and Hsp60 during germ cell apoptosis in the heat-treated testes of adult cynomolgus monkeys (Macaca fascicularis)," Frontiers in Bioscience, vol. 10, no. 3, pp. 3110-3121, 2005.

[155] S. Shefi, P. E. Tarapore, T. J. Walsh, M. Croughan, and P. J. Turek, "Wet heat exposure: a potentially reversible cause of low semen quality in infertile men," The International Brazilian Journal of Urology, vol. 33, no. 1, pp. 50-56, 2007.

[156] A. Jung, M. Eberl, and W.-B. Schill, "Improvement of semen quality by nocturnal scrotal cooling and moderate behavioural change to reduce genital heat stress in men with oligoasthenoteratozoospermia," Reproduction, vol. 121, no. 4, pp. 595-603, 2001.

[157] A. Jung, W.-B. Schill, and H.-C. Schuppe, "Improvement of semen quality by nocturnal scrotal cooling in oligozoospermic men with a history of testicular maldescent," International Journal of Andrology, vol. 28, no. 2, pp. 93-98, 2005.

[158] S.-H. Song, J. J. Lim, J. K. Bang et al., "Evaluation of sperm deoxyribonucleic acid (DNA) damage and effects on embryo development using a mouse cryptorchidism model," Urology, vol. 82, no. 3, pp. 743.e17-743.e23, 2013.

[159] E. I. Cortés-Gutiérrez, M. I. Dávila-Rodríguez, J. L. Fernández et al., "DNA damage in spermatozoa from infertile men with varicocele evaluated by sperm chromatin dispersion and DBDFISH," Archives of Gynecology and Obstetrics, vol. 293, no. 1, pp. 189-196, 2016.

[160] K. Tamakoshi, H. Yatsuya, T. Kondo et al., "The metabolic syndrome is associated with elevated circulating C-reactive protein in healthy reference range, a systemic low-grade inflammatory state," International Journal of Obesity, vol. 27, no. 4, pp. 443449, 2003.
[161] S. Furukawa, T. Fujita, M. Shimabukuro et al., "Increased oxidative stress in obesity and its impact on metabolic syndrome," The Journal of Clinical Investigation, vol. 114, no. 12, pp. 1752-1761, 2004.

[162] U. Paasch, S. Grunewald, J. Kratzsch, and H.-J. Glander, "Obesity and age affect male fertility potential," Fertility and Sterility, vol. 94, no. 7, pp. 2898-2901, 2010.

[163] H. W. Bakos, M. Mitchell, B. P. Setchell, and M. Lane, "The effect of paternal diet-induced obesity on sperm function and fertilization in a mouse model," International Journal of Andrology, vol. 34, no. 5, part 1, pp. 402-410, 2011.

[164] N. Sermondade, C. Faure, L. Fezeu et al., "Obesity and increased risk for oligozoospermia and azoospermia," Archives of Internal Medicine, vol. 172, no. 5, pp. 440-442, 2012.

[165] K. Leisegang, A. Udodong, P. J. D. Bouic, and R. R. Henkel, "Effect of the metabolic syndrome on male reproductive function: a case-controlled pilot study," Andrologia, vol. 46, no. 2, pp. 167-176, 2014.

[166] J. P. Buch, T. F. Kolon, N. Maulik, D. L. Kreutzer, and D. K. Das, "Cytokines stimulate lipid membrane peroxidation of human sperm," Fertility and Sterility, vol. 62, no. 1, pp. 186-188, 1994.

[167] P. Martínez, F. Proverbio, and M. I. Camejo, "Sperm lipid peroxidation and pro-inflammatory cytokines," Asian Journal of Andrology, vol. 9, no. 1, pp. 102-107, 2007.

[168] M. Fraczek and M. Kurpisz, "Inflammatory mediators exert toxic effects of oxidative stress on human spermatozoa," Journal of Andrology, vol. 28, no. 2, pp. 325-333, 2007.

[169] C. Faure, C. Dupont, M. A. Baraibar et al., "In subfertile couple, abdominal fat loss in men is associated with improvement of sperm quality and pregnancy: a case-series," PLoS ONE, vol. 9, Article ID e86300, 2014.

[170] C. Wright, S. Milne, and H. Leeson, "Sperm DNA damage caused by oxidative stress: modifiable clinical, lifestyle and nutritional factors in male infertility," Reproductive BioMedicine Online, vol. 28, no. 6, pp. 684-703, 2014.

[171] Y. J. R. Ménézo, A. Hazout, G. Panteix et al., "Antioxidants to reduce sperm DNA fragmentation: an unexpected adverse effect," Reproductive BioMedicine Online, vol. 14, no. 4, pp. 418421, 2007.

[172] Y. Menezo, D. Evenson, M. Cohen, and B. Dale, "Effect of antioxidants on sperm genetic damage," Advances in Experimental Medicine and Biology, vol. 791, pp. 173-189, 2014. 


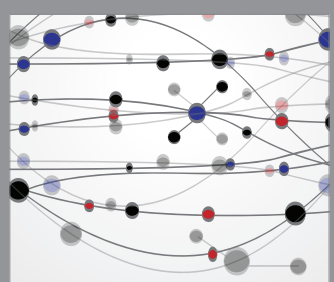

The Scientific World Journal
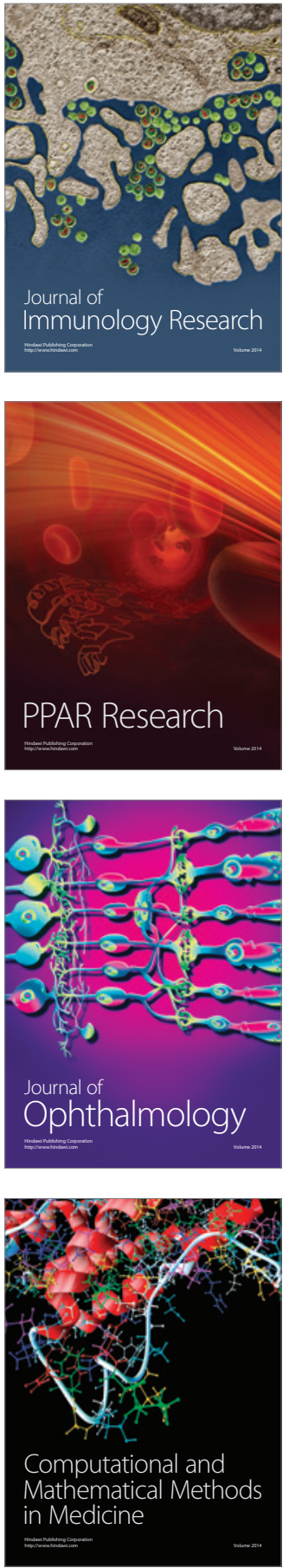

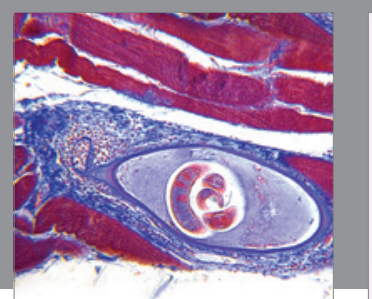

Gastroenterology Research and Practice

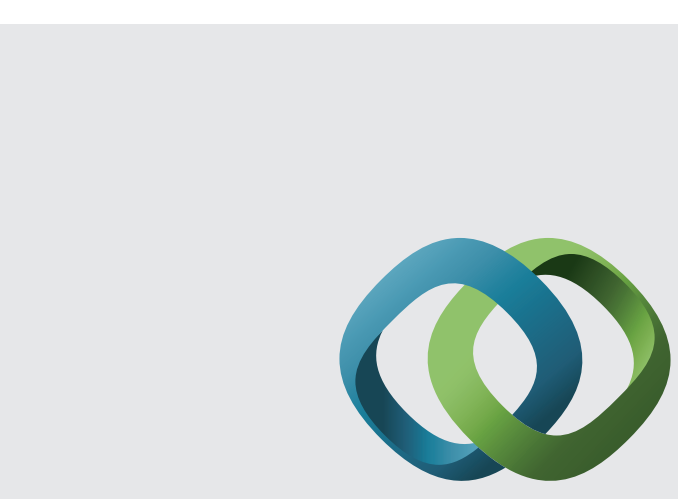

\section{Hindawi}

Submit your manuscripts at

http://www.hindawi.com
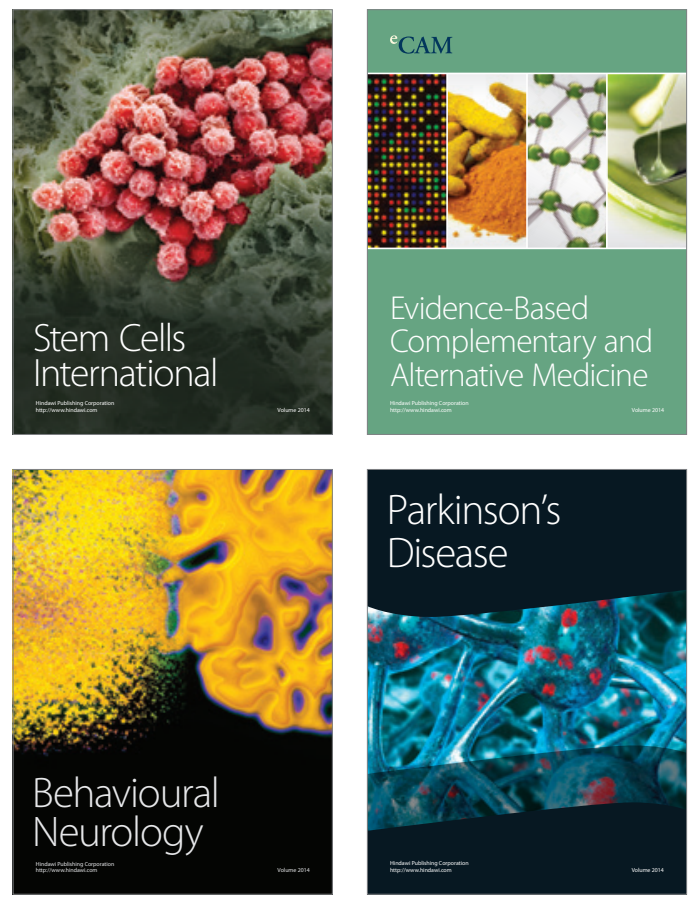
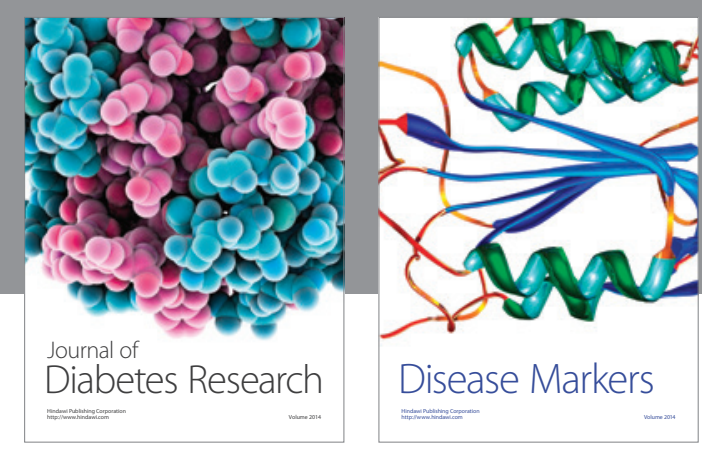

Disease Markers
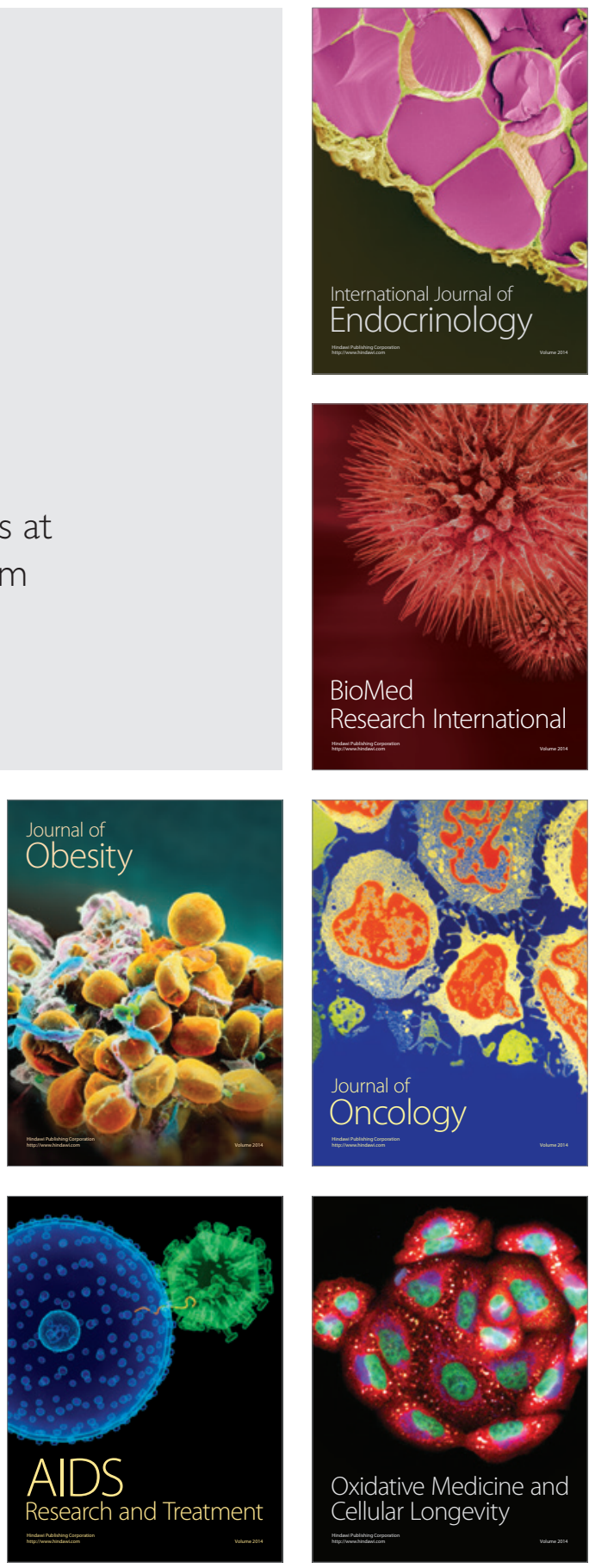